\title{
DIREITO AUTORAL: Como a lei inibe o acesso ao conhecimento.
}

\author{
Kacerine Rodrigues Dias ${ }^{1}$
}

\begin{abstract}
RESUMO: O presente artigo busca estabelecer os pontos conflitantes existentes entre a excessiva proteção aos direitos autorais e a necessidade de a propriedade intelectual exercer de fato a sua verdadeira função social e isso, levando-se em consideração um ambiente, como a internet, que além de permitir a livre manifestação do pensamento também pode funcionar como importante ferramenta de acesso à cultura e ao conhecimento.

Desta forma, defende-se no presente texto que antes de se utilizar da lei específica para o tratamento dos direitos autorais, deve-se primar pela visão constitucional que preza pelo interesse público coletivo e para o desenvolvimento do contingente humano como pessoa protegida pelos preceitos fundamentais expressos na Carta Constitucional de 1988e não simplesmente como ferramenta de trabalho.
\end{abstract}

PALAVRAS CHAVES: DIREITOS DO AUTOR; COOPERAÇÃO; INTERESSE PÚBLICO.

COPYRIGHT: How the law inhibits access to knowledge.

\begin{abstract}
This article aims to establish the conflicting points between the excessive protection for copyright and how it does need to engage in fact its true social function, taking into consideration an environment such as the Internet, which allow the addition of free expression of thought and can also act as an important tool for access to culture and knowledge.

Thus, it is in this text that before the law is used specifically for the treatment of copyrights, it should be precedence for the constitutional vision that values the collective and public interest for the development of the human person as protected by the fundamental precepts expressed in the Constitutional Charter of 1988 e not simply as a work.
\end{abstract}

KEY-WORDS.: COPYRIGHT; COOPERATION; PUBLIC INTEREST

\section{INTRODUÇÃO}

Ao contrário do que era preconizado há séculos atrás, a riqueza das Nações não mensuradas tão somente no seu poderio econômico, mas também no acesso ao conhecimento e às tecnologias de informação que são disponibilizadas a sua população.

Além disso, passou-se a ter uma visão mais abrangente daquilo que é considerado como propriedade, buscando-se prezar pela importância desta frente a sociedade e a sua implicação na vida cultural da mesma.

A criatividade humana frente à estagnação do Direito quando confrontado aos novos anseios da sociedade, fez com que essas novas ferramentas se adaptassem ao Direito de tal forma que atingisse os preceitos constitucionais baseados na valoração do

\footnotetext{
${ }^{1}$ Estudante de Graduação do Curso de Direito da Universidade Federal de Santa Maria(UFSM) - RS. Email: kace_dias@yahoo.com.br

(C) 2008. Departamento de Direito da UFSM. Todos os direitos reservados.
} 
coletivo. O que era simplesmente considerado como "meu' passou a ser objeto de interesse coletivo.

Para um melhor entendimento desse processo de transição, deve-se levar em consideração os aspectos históricos do conceito de direito autoral, assim como as primeiras tentativas de proteção do mesmo, até a necessidade atual que é a de exercício por parte da propriedade intelectual da função social e as formas colaborativas que foram criadas para que tal princípio constitucional definitivamente começasse a ser concretizado.

\section{CONTEXTO HISTÓRICO DOS DIREITOS AUTORAIS}

A Idade Média caracterizou-se principalmente pelo surgimento das grandes extensões de terra, concentradas na figura de um único senhorio. A riqueza de um feudo era mensurado conforme a sua extensão e conforme a influência e poder do senhor feudal sobre seus vassalos.

Nesta época, o conhecimento era monopólio da Igreja, sendo repassado somente para quem possuía condições de pagar pelo mesmo. Foi nessa época que surgiram as primeiras Universidades, sendo que a primeira foi a Escola de Direito da Bolonha.

$\mathrm{Na}$ verdade, o surgimento das Universidades esteve estritamente ligado a revitalização do comércio e ressurgimento das cidades. Ressalte-se que nessa época, com o ideário "cosmopolita" de expansão da fé, maquilado pelo interesse eminentemente econômico de expansão de poder, deu-se início ao movimento das Cruzadas, o que ocasionou um grande desenvolvimento do comércio, das cidades e o surgimento de inúmeros grupos sociais interessados em auferir lucros frente a nova forma de economia. Surgiu aí a burguesia.

No século XIV, com o intuito de rechaçar o monopólio da cultura e do conhecimento que era exercido pela Igreja Católica, adveio o tempo da Renascença. Esta nova era se caracterizou principalmente sob o ponto de vista de dois aspectos: o advento da visão antropocentrista do homem, ou seja, passou-se a posicionar o ser humano como centro das atenções, indagações e preocupações por parte dos pensadores e, do ponto de vista econômico-cultural, salienta-se as riquezas que passaram a ser acumuladas pela burguesia, camada social esta que passou a financiar a produção das obras de escritores e artistas. 
Por certo que, tendo em vista o poderio econômico dos mecenas, não era simplesmente a difusão cultural que eles pretendiam, mas sim, como todo bom burguês, a ascensão social. Foi nessa época, que Johannes Gutenberg (1445), revolucionou o processo de produção de livros, permitindo a difusão das idéias humanistas para um número cada vez maior de pessoas.

Nessa época foi criado o regime de privilégio, que conforme ensinamento do douto Manoel J. Pereira dos Santos $(2008)^{2}$ possui três finalidades intrínsecas: (i) regular as atividades de impressão e o comércio de livros; (ii) restringir a concorrência desleal entre editores e livreiros e por fim (iii) controlar a circulação de obras através de prévia censura.

Apesar de datar do século XV a invenção que proporcionou uma maior disponibização das obras, somente no início do século XVIII, passou-se a proteger o direito daqueles que através da criatividade e conhecimento, eram capazes de disseminar idéias organizadas na forma de obras literárias. Na Inglaterra, através do Ato da Rainha Ana, passou-se a conceber o direito do autor como um privilégio. Este ato, não considerava a obra como objeto diretamente ligado à personalidade do autor, sendo tão somente uma concessão, um ato de benevolência concedido pela Coroa.

Não obstante isso, a lei beneficiava somente a classe dos livreiros que comercializava as obras. Os autores continuavam sentindo fome e sendo acometidos pelas mais diversas moléstias, pois os editores e livreiros continuavam se aproveitando as situações de ignorância comercial dos mesmos. Isto se dava principalmente quando aos autores cediam os direitos patrimoniais de suas obras para os editores/livreiros, para melhor comercializarem as obras, e sendo assim, de fato, serem agraciados com o benefício do lucro. Tal fato, só foi presenteado com a relevância merecida na época da Revolução Francesa, que passou a reconhecer o viés patrimonial inerente ao direito autoral. O moral ainda não era levado em consideração, conforme preconiza Rodrigo Moraes (2006)

O conteúdo moral somente começou a despontar no século XIX, sendo construído pela jurisprudência. O autoralista italiano Piola Caselli foi o autor da introdução do direito moral no texto da Convenção de Berna (art. 6 bis), revisada em Roma, em 1928. Essa Convenção consiste no primeiro e mais

\footnotetext{
${ }^{2}$ SANTOS, Manoel J. Pereira. II Congresso de Direito de Autor e Interesse Público e Fórum Nacional de Direito Autoral. Florianópolis, 16 de junho de 2008.
}

(C) 2008. Departamento de Direito da UFSM. Todos os direitos reservados. 
importante instrumento internacional versando sobre Direito Autoral. Assinada na capital da Suíça, em 1886, ainda está em vigor nos dias atuais. ${ }^{3}$

O Código Civil revogado, também não reconhecia o valor moral às obras, uma vez que, permitia a cessão completa da autoria das obras, o que pode ser considerado como verdadeira aberração jurídica, uma vez que direitos de personalidade são indisponíveis, inalienáveis e estão estritamente ligados aos processo de criação dos autores.

O autor, quando se encontra no seu momento de criação, reveste sua obra de todos os sentimentos que o atormentam naquele singular momento de criação. São amores, tristezas, temores, experiências que tornam a obra de importância ímpar. È a capacidade do ser humano de se emocionar e de reagir das mais diversas formas a cada fator externo que o torna um ser complexo. E quando ele é capaz de exteriorizar suas vivências, experiências e dramas em obras, sejam literárias, sejam musicais, ou através de uma pintura, é inadmissível a celebração de um contrato onde o autor dispõe de ter seu nome vinculado àquela obra de importância ímpar.

O saudoso mestre Clóvis Bevilaqua (1923), compartilha do mesmo pensamento, quando exterioriza em sua obra o seguinte ensinamento:

O que se contesta é que o autor possa despojar-se dessa irradiação da sua personalidade, que se manifesta vínculo indestrutível entre o seu espírito e a obra, que ele criou. E contesta-se, não somente em nome da lógica jurídica, violentada por essa construção, como, também, por motivos de ordem moral, que, aliás, não escaparam ao ilustre parlamentar brasileiro. Afastou-se, porém, pensando melhor favorecer algum pobre diabo de talento, que consiga viver à custa da "vaidade", ridícula sem dúvida, mas não injurídica do incapaz, que quer passar como autor. Não será injurídica essa vaidade, mas, igualmente, não deve o direito fomentar a mistificação do público. ${ }^{4}$

$O$ artigo 667 facultou ao autor a cessão gratuita ou onerosa de sua autoria. $O$ retrocesso do Código Civil de 1916 trouxe conseqüências maléficas para o

3 MORAES, Rodrigo. A função social da propriedade intelectual na era das novas tecnologias. Disponível em <http://www.cultura.gov.br/site/?cat=1351>, p.255

${ }^{4}$ BEVILÁQUA, Clóvis. Código Civil Comentado. 2. ed. Rio de Janeiro: Editora Livraria Francisco Alves, 1923, p. 203-204, v. III.

(C) 2008. Departamento de Direito da UFSM. Todos os direitos reservados. 
Direito Autoral. Por muito tempo foi permitida a compra de autoria, o que deu ensejo à proliferação da nefasta prática dos "comprositores", .

Notoriamente reconhecido o retrocesso subjetivo reconhecido ao autor pelo ordenamento jurídico vigente à época, com o advento da Constituição Federal de 88 e a Lei n ${ }^{\circ} .9 .610 / 98$, passou-se a compartilhar do ideário da teoria dualista que reconhece os direitos de ordem moral e de ordem material dos direitos autorais. ${ }^{6}$ Com isso, passou-se a reconhecer o autor como protagonista da história cultural da sociedade, punindo diretamente aqueles que por algum motivo causam danos de ordem subjetiva ao autor, sem contudo preterir os danos de ordem patrimonial.

\section{BREVES CONSIDERAÇÕES CONTRATUAIS SOBRE DIREITO AUTORAL.}

No regime de direito autoral brasileiro pode-se afirmar que existem duas características a ele são inerentes: a de direito patrimonial, que permite que o mesmo seja transferido de forma onerosa ou gratuita, pelo autor ou por seus herdeiros, até essa cair em domínio público e a moral que pode ser considerada como a emanação da personalidade do autor, sendo intransferível, impenhorável, imprescritível e oponível erga omnes.

A lei brasileira, em seu art. $3^{\circ}$ considera os direitos autorais como bens móveis, que conforme o art. 82 do Código Civil brasileiro são aqueles bens suscetíveis de movimento próprio, ou removíveis através de fora alheia, sem alteração de sua substância ou da destinação econômico-social.

No entanto, o ponto mais interessante a ser ressaltado na legislação brasileira diz respeito às normas contratuais que regem tal instituto. Neste regime a LDA, em seu art. $4^{\circ}$ determina que os mesmos devem ser interpretados de forma restritiva, ou seja,

\footnotetext{
${ }^{5}$ Vide cit. 1.

6 “Art. 24. São direitos morais do autor: (I) o de reivindicar, a qualquer tempo, a autoria da obra; (II) - o de ter seu nome, pseudônimo ou sinal convencional indicado ou anunciado, como sendo o do autor, na utilização de sua obra;(III) o de conservar a obra inédita;(IV) - o de assegurar a integridade; (IV)da obra, opondo-se a quaisquer modificações ou à prática de atos que, de qualquer forma, possam prejudicá-la ou atingi-lo, como autor, em sua reputação ou honra;(V)- o de modificar a obra, antes ou depois de utilizada; (VI) - o de retirar de circulação a obra ou de suspender qualquer forma de utilização já autorizada, quando a circulação ou utilização implicarem afronta à sua reputação e imagem;(VII) - o de ter acesso a exemplar único e raro da obra, quando se encontre legitimamente em poder de outrem, para o fim de, por meio de processo fotográfico ou assemelhado, ou audiovisual, preservar sua memória, de forma que cause o menor inconveniente possível a seu detentor, que, em todo caso, será indenizado de qualquer dano ou prejuizo que lhe seja causado."
}

(C) 2008. Departamento de Direito da UFSM. Todos os direitos reservados. 
"tudo que não estiver expressamente previsto no contrato, ou no negócio, entende-se como não autorizado. Não há a possibilidade e 3 w3 dar efeito extensivo a nenhuma cláusula do contrato, e muito menos a de o contratado transmitir os direitos recebidos do autor a terceiro, sem o seu expresso consentimento nesse sentido"7

Já o art. 49 da LDA dispõe que os direitos de autor poderão ser transferidos, que poderá se dar tanto a título universal como singular e será efetivada através de licença ou cessão. A cessão, que pode ser total ou parcial, se caracteriza pela transferência de titularidade e a licença por uma autorização que parte do autor para que terceiro se valha da obra, nos termos da autorização concedida.

Ainda deve ser ressaltado que mesmo que não exista disposição expressa, um contrato de direito autoral sempre se presume oneroso, para que seja considerada como gratuita a transferência de direitos sobre o material, tal ato deve estar expresso em cláusula específica.

\section{O DIREITO AUTORAL E A INTERNET.}

"Uma mudança deixa sempre o caminho aplainado para a edificação de outra" (Maquiavel)

Através do advento da Internet e a sua presença constante na vida da grande maioria dos indivíduos, o regime do direito autoral passou a se deparar com um novo desafio e isso, acabou demonstrando o quão rapidamente as legislações são capazes de se tornar obsoletas frente a evolução humana na busca do conhecimento.

Através da criação de um novo conceito de sociedade e desenvolvimento baseado no acesso ao conhecimento passou-se a ter a Internet como um ambiente favorável a este processo. Isto porque, este novo ambiente permite troca de informações em velocidade até duas décadas inimagináveis, possibilitando que o conhecimento atingisse cada vez um número maior de indivíduos.

Porém, muitas vezes o conteúdo que é disponibilizado na rede não atende às diretrizes impostas pela restritiva Lei de Direitos Autorais. Principalmente quando há o compartilhamento na íntegra de músicas ou obras literárias, já que a lei, permite a cópia apenas de pequenos trechos. No entanto, muitas das obras literárias que são

\footnotetext{
${ }^{7}$ ABRÃO, Eliane Y. Direitos de Autor e Direitos Conexos. Cit.,p.37.

(C) 2008. Departamento de Direito da UFSM. Todos os direitos reservados.
} 
disponibilizadas na íntegra, ou se encontram fora dos catálogos de venda das editoras, ou é são oferecidas em um número muito limitado e insuficiente para a demanda.

Afirma-se tal fato, por exemplo, quando depara-se com a realidade das bibliotecas acadêmicas que muitas vezes disponibilizam apenas um exemplar de uma obra já esgotada para um mar de quarenta alunos. A reprodução e disponibilização é vedada. No entanto, é justo afirmar que estes alunos poderão ser responsabilizados civilmente por simplesmente buscarem facilitar o acesso deles e de outras pessoas à obra? É correto afirmar que deve-se sobrepor um interesse individual em face de um interesse coletivo?

A internet é um ambiente baseado na cooperação, prova disso foi o surgimento de inúmeras formas avessas aos conceitos impostos pela legislação brasileira. Tanto no que diz respeito à despersonalização do autor e a elaboração de obras a partir de um conceito de colaboração, como o desenvolvimento de instrumentos jurídicos permissivos, ou seja, que possibilitam a cópia na íntegra e a livre disponibilização de obras, desde que sem fins lucrativos.

Para elucidar essa perspectiva de cooperação frente ao direito autoral, pertinente se mostra as colocações de Ronaldo Lemos, no que se refere ao que ele chama de transformação construtiva da propriedade intelectual ${ }^{8}$, citando o movimento do software livre como intróito das diversas formas colaborativas de produção.

Partindo dessa idéia, hoje o sistema operacional Linux, é considerado por muitos programadores como superior ao sistema criado pela Microsoft, uma vez que o seu desenvolvimento não tem um intuito econômico, mas sim, qualitativo. Busca-se criar um programa bom o suficiente, para quebrar o monopólio econômico criado pela detentora da marca Windows a ponto de facilitar o acesso da população à tecnologia e ao conhecimento.

$\mathrm{O}$ avanço foi tanto, que até mesmo as máquinas que passaram a ser vendidas com esse sistema operacional instalado em seu disco rígido, passaram a ter preços mais acessíveis para a população. Partiu-se de uma idéia colaborativa, para um fim de inclusão social, que sem algum objetivo econômico, passou a favorecer grande parte da sociedade.

Nas palavras de Ronaldo Lemos (2006), grande idealizador deste sistema colaborativo no Brasil "Muitos (agentes) fazem isso porque consideram esta atividade

8 LEMOS, Ronaldo. Direito, Tecnologia e Cultura. Obra disponível na integra no site <http:www.overmundo.com.br/banco/livro-direito-tecnologia-e-cultura-ronaldo-lemos>

(C) 2008. Departamento de Direito da UFSM. Todos os direitos reservados. 
divertida, outros o fazem porque acreditam estar retribuindo conhecimento à sociedade, e outros ainda porque passam a se sentir parte de uma iniciativa global, que pode beneficiar diretamente centenas de milhares de pessoas, senão a humanidade como um todo.".

Outro exemplo bastante pertinente, a cerca da nova perspectiva de autor é a wikipédia, enciclopédia interativa, que conta com a colaboração de internautas detentores de algum conhecimento sobre um caso histórico, geográfico, técnico específico e que tenham o intuito de repassar para a coletividade esse determinado conhecimento. E como a criatividade brasileira não poderia ser relegada a segundo plano, criou-se também, um "mapa mundi" interativo que tem como objetivo mapear o crime no país. Todas as pessoas que porventura tenham sido assaltadas podem colaborar, pontuando no mapa a localização da ocorrência do crime.

Há ainda, a política do acesso aberto que permite a livre disponibilização de publicações científicas na internet facilitando com isso a interação entre as universidades, a troca de informações a cerca das pesquisas desenvolvidas, aumentando com isso, o número de citações por artigos, fator relevante para os órgãos de fomento à pesquisa.

A partir da idéia do princípio cooperativo e colaborativo, atinge-se o Interesse Público que conjuga essa nova forma de pensar: se a cultura, a educação e o acesso à informação foram elevados a garantias constitucionais após a Carta Magna de 88, é correto privar a coletividade do acesso às mesmas em detrimento de interesses individuais? A atual sistemática do direito autoral não é demasiadamente protecionista a ponto de dificultar o acesso da população às obras? Não deveria o ente Estatal primar pelo desenvolvimento das formas colaborativas de acesso ao conhecimento e à informação, como forma de aprimoramento do fator humano nacional?

As respostas para as indagações poderiam se encontrar de forma clara no próprio texto constitucional, quando em seu terceiro capítulo art. 205 afirma ser o Estado responsável pela educação, e que esta deve acontecer com a colaboração da sociedade ${ }^{9}$, porém, há contradições quando seguindo o conteúdo constitucional nos deparamos com os seguintes artigos: artigo 206, inciso II, que “o ensino será ministrado com base nos seguintes princípios: liberdade de aprender, ensinar, pesquisar e divulgar o pensamento,

\footnotetext{
9 Art. 205. A educação, direito de todos e dever do Estado e da família, será promovida e incentivada com a colaboração da sociedade, visando ao pleno desenvolvimento da pessoa, seu preparo para o exercício da cidadania e sua qualificação para o trabalho.
}

(C) 2008. Departamento de Direito da UFSM. Todos os direitos reservados. 
a arte e o saber"; art. 208, inciso V, garante que o Estado é o responsável pelo "acesso aos níveis mais elevados do ensino, da pesquisa e da criação artística, segundo a capacidade de cada um"; art. 215 afirma que o Estado garantirá o acesso às fontes da cultura nacional e que apoiará e incentivará a valorização e a difusão das manifestações culturais. No artigo 216, incisos I, III e IV, considera as "formas de expressão", "as criações científicas, artísticas e tecnológicas" e as "obras, (...) documentos, (...) destinados às manifestações artístico-culturais" como constituintes do patrimônio cultural brasileiro, que tem seu acesso garantido pelo artigo anterior. Torna-se latente, a dificuldade de se equilibrar os interesses coletivos com os do autor.

Por isso, deve haver uma conjugação de interesses, em busca do fim comum que o acesso à cultura e ao conhecimento. Repete-se com isso, que esse objetivo deve surgir a partir da idéia de colaboração e cooperação. E essas idéias já se encontram presentes no mundo cibernético o qual não encontra barreiras para a disseminação do conhecimento. As informações tramitam em velocidades até duas décadas inimagináveis, e anos-luz a frente das legislações. Existe um ambiente propício à liberdade de expressão e para livre circulação de informações.

Este "boom" cultural tem como causa direta as políticas governamentais de inclusão digital, está-se permitindo um maior acesso ao mundo tecnológico. Porém, toda essa liberdade, trouxe a tona a problemática do controle dos direitos autorais e a ilegalidade de muito material que "circula pela rede". Justamente porque na rede não há propriedade, mas tão somente a função social. É a partir dessa função social do livre acesso, que hoje se permite medir a riqueza das nações. O poder econômico deve estar conjugado com o poder de conhecimento que essa nação possui, e não se deve limitar o pensamento ao número de patentes registradas no pais durante um ano, ou determinada época, mas sim, na capacidade de seu corpo populacional de ter acesso, assimilar e responder de forma crítica àquele conteúdo que a ele está sendo disponibilizado.

Ademais, a grande discussão hoje pode ser centralizada na grande disparidade existente entre os países com acesso à informação e os destituídos da mesma. O que torna um grande fator de grande relevância para efeitos de participação no mercado global, conforme denota Aline Vitalis (2006), em seu trabalho "A função social dos direitos autorais: uma perspectiva constitucional e os novos desafios da sociedade de informação" 
Para embasar sociologicamente essa nova percepção de direitos autorais, deve-se ressaltar ainda o pensamento de Hegel que apregoava que o homem não existe sozinho. Em sua teoria, cada ser humano individualmente é síntese histórica de toda a humanidade, não existindo, destarte, conhecimento de um único indivíduo, mas esse indivíduo é livre e sua criatividade deve ser valorizada.

Não se pretende acabar com o instituto dos direitos autorais, correta é a necessidade de proteção outorgada àqueles que dispõem da criatividade como forma de laboro, no entanto, deve-se buscar uma flexibilização e uma motivação social para a inserção das formas colaborativas de criação. De forma que se permita o livre acesso às obras em alguns casos e o aprimoramento das mesmas como por exemplo no caso dos programas de computador, que são protegidos pelo instituto dos direitos autorais.

Grande questão que merece respaldo são os artigos e obras de cunho científico, literário e cultural, que, na maioria das vezes, em virtude dos valores agregados que são cobrados, e devem ser pagos a editora, a livraria, a gráfica e ao autor da obra, quando encontram no final desta cadeia o consumidor (o estudante, enfim, o indivíduo em busca do conhecimento), torna-se caro e inviável de ser adquirido pelas formas "legais", sendo que muitas vezes, estudantes são obrigados a recorrer à formas alternativas de acesso às obras, como por exemplo, reproduzindo-as integralmente, ou muitas vezes, realizando o "download" das mesmas, já que inúmeras são as obras disponibilizadas na íntegra na rede, e que ainda não são consideradas como domínio público

A Lei $\mathrm{n}^{\circ}$ 9.610/98, em seu art. 46, inc. II, somente permite a cópia de pequenos trechos, para uso privado, sem intuito de lucro. A cópia integral somente é aceita mediante autorização do autor, no entanto, quando existe a mediação das editoras entre o consumidor e o autor, tal benesse torna-se praticamente impossível.

De outra feita, o art. 24, inciso IV da supracitada lei, assegura a integridade da obra, opondo modificações ou a prática de atos que possam prejudicar a imagem do autor. Porém, quando essas modificações puderem ser inseridas de forma a melhorar a obra e o seu conteúdo, também estará o indivíduo agindo às sombras da lei?

Não obstante isso, é de se considerar exagerado o tempo de proteção ao direito autoral, já que protege a obra durante o período de setenta anos após a morte do autor, quando, por exemplo, nos países desenvolvidos como os Estados Unidos, o prazo para que a obra seja reconhecida como de domínio público, e sendo assim, ser 
disponibilizada, por exemplo, nos meios virtuais, através de e-books, começa a fluir a partir da publicação da obra.

Afinal, se o direito autoral se reveste de caráter personalíssimo, inalienável e intransmissível, por que prorrogar por tanto tempo essa proteção exacerbada? Setenta anos após a morte do autor, se hoje se sabe que as editoras continuam lucrando exacerbadamente sobre a venda das obras?

Acredita-se que seria demasiada ousadia requerer uma mudança legislativa no prazo protecional, uma vez que são inúmeros os países que compartilham destes prazos, considerados, repito, ao meu ver, exacerbados. Contudo, acredita-se que o Direito não deve buscar simplesmente ser a boca morta e fria do Congresso Nacional, mas sim, primar pelo busca da harmonia social, e como os consagrados autores da Literatura Nacional e Mundial, ser criativo, a ponto de se adaptar aos novos paradigmas que se formam.

Para o mundo do direito autoral já pode-se afirmar que surgiu a primeira forma de adaptação que são as chamadas licenças Creative Commons, que nada mais são conforme Ségio Vieira Branco (2007) que:

instrumentos jurídicos para que um autor, um criador ou uma entidade diga de modo claro e preciso, para as pessoas em geral, que uma determinada obra intelectual sua é livre para distribuição, cópia e utilização. Essas licenças criam uma alternativa ao direito da propriedade intelectual tradicional, fundada de baixo para cima, isto é, em vez de criadas por lei, elas se fundamentam no exercício das prerrogativas que cada indivíduo tem, como autor, de permitir o acesso às suas obras e a seus trabalhos, autorizando que outros possam utilizá-los e criar sobre eles ${ }^{10}$.

$\mathrm{Na}$ mesma obra, ainda merece respaldo a seguinte colocação pela pertinência e pela simplicidade como foi exposta pelo mesmo autor: "Um dos principais problemas do direito autoral “clássico” é que ele funciona como um grande "NÃO!”. É comum encontrar, em obras autorais exploradas economicamente, a inscrição "Todos os Direitos Reservados" (ou "All Rights Reserved”). Isso quer dizer que, se alguém

${ }^{10}$ Lemos, Ronaldo. Direito, Tecnologia e Cultura. Pág. 83.

(C) 2008. Departamento de Direito da UFSM. Todos os direitos reservados. 
pretende utilizar aquela obra, tem de pedir autorização prévia a seu autor ou detentor de direitos. ",11

Essas licenças não buscam preterir a legislação vigente, mas sim adaptar a mesma a cada caso. Ademais, elas são uma alternativa às diretrizes negativas da lei, quando permitem a livre manipulação, distribuição, compartilhamento e replicação dos conteúdos das obras. Ademais deve-se ousar dizer que a utilização de tais licenças em muito beneficiam os autores, já que suas obras poderão atingir às mais diversas camadas da sociedade e não apenas aos que podem pagar pelo acesso as mesmas.

Inúmeros são os exemplos das formas colaborativas e cooperativas que buscam facilitar o acesso da população à cultura, como por exemplo, o Projeto Gutemberg ${ }^{12}$ que consiste em uma biblioteca virtual que possui na íntegra o conteúdo de obras que constam em domínio público ou obras que tiveram seus direitos cedidos pelos autores; há ainda a nova cultura de utilização de software livre que permite que haja um aprimoramento do programa baseado no princípio da colaboração; diversos sítios na internet que disponibilizam material de palestras e seminários em prol do livre acesso ao conhecimento, e até mesmo, como na cidade de Santa Maria - RS, existe a Cooperativa de Estudantes de Santa Maria - Cesma - que através dessa forma de organização societária busca fornecer aos estudantes associados, descontos extremamente consideráveis nos preços quando na aquisição das obras.

De singular importância se torna a posição de Sérvio Vieira Branco Júnior(2007) em sua inovadora obra ${ }^{13}$ sobre as formas colaborativas, que assevera:

o que existe é, a rigor, o avesso do conceito de autor: o direito do autor fica em segundo plano e muitos participam de obras colaborativas” e mais adiante ${ }^{14}$ “ As obras colaborativas podem vir a ser, a rigor, a efetivação, dentro do campo de direitos autorais, do disposto no art. 4, I, de nossa Constituição Federal, que objetiva a construção de uma sociedade mais solidária, que entende por liberdade de expressão, a ajuda mútua e o compartilhamento de conhecimento podem valer mais do que a preservação de direitos autorais, muitas vezes, de pouco espectro. (grifo nosso)

\footnotetext{
${ }^{11}$ Vide cit. 17.

12 <http://www.gutenber.org>

${ }^{13}$ BRANCO, Sérgio Vieira. Direitos autorais na Internet e o Uso de Obras Alheias. Cit., p. 171

${ }^{14}$ BRANCO, Sérgio Vieira. Direitos autorais na Internet e o Uso de Obras Alheias. Cit., p. 173
} 
Como já dito anteriormente, essas formas cooperativas, colaborativas, fundadas no interesse público não ferem a legislação específica do direito autoral, muito pelo contrário, ela preconiza o disposto na Constituição Federal e faz com que o Direito se adapte às novas dimensões que as fronteiras (se é que ainda existem) tomaram.

\section{CONSIDERAÇÕES FINAIS}

A sociedade e as suas necessidades evoluíram de tal forma frente ao avanço tecnológico que o Direito ainda engatinha na busca da adaptação à nova realidade. A propriedade não é mais vista como algo absoluto, embora alguns artigos do novel Código Civil exponham que sim. A constituição prima pelo interesse coletivo, mas a Legislação Autoral, em certos pontos, pretere esse interesse público. No entanto, como possuímos uma das Constituições mais evoluídas entre as Nações, devemos prezar pela visão constitucional do todo.

É através dessa proposta de preocupação em prol do interesse público que as novas legislações e adaptações legais devem primar. O Direito, como principal instrumento de acesso da população pela busca da efetiva justiça deve buscar se adaptar a nova realidade social e não simplesmente negar a existência dessas necessidades alegando o confronto direto entre o interesse e a lei.

Os indivíduos em busca de conhecimento e cultura não querem as restrições e imposições dispostas nas legislações específicas, mas sim, a efetivação das garantias dispostas no texto supremo da Constituição Federal de 1988.

\section{REFERÊNCIAS BIBLIOGRÁFICAS}

ABRÂO. Eliane Y. Direitos de Autor e Direitos Conexos. $1^{\text {a }}$ edição. São Paulo. Editora do Brasil. 2002.

BARRETO, Lucas Hayne Dantas. Função Social da Propriedade: análise histórica. Disponível em <http://jus2.uol.com.br/doutrina/texto.asp?id=7164>. Acesso em 14 de maio de 2008.

BEVILÁQUA, Clóvis. Código Civil Comentado. 2. ed. Rio de Janeiro: Editora Livraria Francisco Alves, 1923, p. 203-204, v. III. 
BRANCO, Sérgio Vieira. Direitos Autorais na Internet e o Uso de Obras Alheias. $1^{\text {a }}$ edição. Rio de Janeiro. Lúmen Júris. 2007.

LEMOS, Ronaldo. Direito, Tecnologia e Cultura. Obra disponível na integra no site <http:www.overmundo.com.br/banco/livro-direito-tecnologia-e-cultura-ronaldolemos>. Download em: 15 de abril de 2008.

MORAES, Rodrigo. A função social da propriedade intelectual na era das novas tecnologias. Disponível em <http://www.rodrigomoraes.adv.br/monografia.pdf $>$. Acesso em: 02 de maio de 2008.

PEREIRA, Fábio Barbosa. A eficácia do direito autoral face à sociedade da informação: uma questão de instrumentalização na obra musical. Disponível em $<$ http://www.cultura.gov.br/site/?cat=1351>

PIOVESAN, Flávia. Direitos Humanos e Propriedade Intelectual. Disponível em http://www.culturalivre.org.br. Acesso em 04 de maio de 2008.

TEIZEN. Augusto Geraldo. A função social no Código Civil. $1^{\text {a }}$ edição. São Paulo. Ed. Revisto dos Tribunais. 2004.

VIANNA, Túlio. A Ideologia da Propriedade Intelectual: a inconstitucionalidade da tutela penal dos direitos patrimoniais de autor., p. 3. Disponível em http://bdjur.stj.gov.br/dspace/bitstream/2011/8625/4/A_ideologia_da_propriedade_intel ectual.pdf> Acesso em 04 de abril de 2008.

VITALIS, Aline. A eficácia do direito autoral frente à sociedade de informação. Disponível em <http://www.cultura.gov.br/site/wp-content/uploads/2008/02/cadernopoliticas-culturais-direitos-autorais.pdf.> Acesso em 28 de abril de 2008. 
